\title{
Tannin-caprolactam and Tannin-PEG formulations as outdoor wood preservatives: weathering properties
}

\author{
Gianluca Tondi ${ }^{1}$. Jinbo Hu ${ }^{2,3}$ - Filippo Rizzo ${ }^{1}$ Janez Buh ${ }^{4}$ - Sergej Medved ${ }^{4}$. \\ Alexander Petutschnigg ${ }^{1} \cdot$ Marie-France Thevenon $^{3}$
}

Received: 7 August 2016 / Accepted: 21 October 2016/Published online: 15 February 2017

(C) The Author(s) 2017. This article is published with open access at Springerlink.com

\begin{abstract}
- Key message This article presents the leaching, fire and weathering resistance improvements of samples treated with tannin-based wood preservatives added of caprolactam. PEG-added formulations show limited applicability. The FT-IR and ${ }^{13} \mathrm{C}$-NMR analyses of the caprolactam-added formulations show some evidences of copolymerization.
\end{abstract}

Handling Editor: Jean-Michel Leban

Contribution of the co-authors

Gianluca Tondi: research leader, formulation developer, publication writing and data analysis

Jinbo Hu: sample preparation and fire testing

Filippo Rizzo: responsible for the weathering test and the CIELAB system

Janez Buh: sample preparation and retention studies

Sergej Medved: writing

Alexander Petutschnigg: multivariate data analysis

Marie-France Thevenon: research leader, publication writing and sample preparation

Gianluca Tondi

gianluca.tondi@fh-salzburg.ac.at

Jinbo $\mathrm{Hu}$

hjb1999@hotmail.com

Filippo Rizzo

frizzo.htw-m2012@fh-salzburg.ac.at

Janez Buh

Jbuh@bf.uni-lj.si

Sergej Medved

sergej.medved@bf.uni-lj.si

Alexander Petutschnigg

alexander.petutschnigg@fh-salzburg.ac.at
- Context Tannin-boron wood preservatives are known for their high resistance against leaching, biological attacks, fire as well as for the good mechanical properties that they impart to wood. These properties promoted these formulations for being a candidate for the protection of green buildings. However, the low elasticity of these polymers and their dark colour implied limited weathering resistances.

- Aims The aim of the study is to find suitable additives for tannin-based formulations to overcome their limited weathering resistances, without compromising the other properties.

- Methods Treatment, leaching and fire tests, dimensional stability as well as artificial and natural weathering of the timber treated with caprolactam-added and PEG-added formulations were performed. FT-IR and ${ }^{13} \mathrm{C}-\mathrm{NMR}$ of the formulations were presented.

- Results The presence of caprolactam improved the properties of the formulation with particularly significant results in terms of resistance against leaching and dimensional stability. These enhancements were imparted also to the weathering resistance of the tannin-caprolactam formulations. Indeed,

Marie-France Thevenon

marie-france.thevenon@cirad.fr

1 Forest Product Technology and Timber Construction Department, Salzburg University of Applied Sciences, Marktstraße 136a, 5431, Kuchl, Austria

2 College of Material Science and Engineering, Central South University of Forestry and Technology, Shaoshan South Road, No. 498, Changsha 410018, China

3 Research Unit BIOWooEB, TA B 114/16, CIRAD, Cedex 5, 34398 Montpellier, France

4 Biotechnical Faculty, Department of Wood Science and Technology, University of Ljubljana, Rozna dolina, cesta VIII/34, 1000 Ljubljana, Slovenia 
the colour changes during the artificial and natural exposures were stable for longer periods. FT-IR and ${ }^{13} \mathrm{C}$-NMR investigations of the advanced formulations were led, and covalent copolymerization of the caprolactam with the tanninhexamine polymer was observed.

- Conclusion The tannin formulations with caprolactam improved the durability of the wood specimens, while the PEGtannin presented strong application drawbacks.

Keywords Condensed tannin - Timber protection · CIELAB system $\cdot$ Natural copolymer $\cdot$ Multivariate data analysis $\cdot$ PCA

\section{Introduction}

In former times, universal solutions for preserving wood were used: Creosote, pentachlorophenol and then chromate-copperarsenate (CCA) were dominating the market warranting very long service life (Richardson 1993; Ruddick 2011). Since over a decade, bans and restrictions on the use of these wood preservatives have focused attention on technological developments of alternatives in wood protection area (Evans 2003; Schultz et al. 2007; 98/8/EC 1998; 2003/2/EC 2003; 2011/71/EU 2011).

As the wood protection sector is getting under scrutiny, different alternative systems, mainly based on natural solutions, are receiving more attention (Singh and Singh 2012; Mai et al. 2004). Amongst different approaches, the addition of hydrophobic substances in order to hinder the access to water enhancing the durability of wood especially against fungal agents is one of the most suited solutions. Wood protection can be improved by the use of oil and waxes (Treu et al. 2004; Lesar and Humar 2011), as well as tall oil, a secondary product of the pulp and paper industry (Hyvönen et al. 2006), or pyrolysis fractions (Temiz et al. 2010; Palanti et al. 2011; Mazela 2007). Other alternative solutions based on lactic acid and proteins were also studied with promising results (Nöel et al. 2009a,b; Thevenon et al. 1997; Thévenon and Pizzi 2003; Polus-Ratajczak and Mazela 2004). Other researchers have published studies in which the hydrophobic matrix was mixed to an active biocide in order to enhance its protective effect (Evans et al. 2009; Temiz et al. 2008; Yang et al. 2006).

The technology applied in this work exploits the properties of tannins to its utmost as: On one hand, they are easily soluble in water, and therefore, they can penetrate into wood (Tondi et al. 2013a), and on the other hand, they can polymerize in situ increasing the hydrophobicity of the wood surface (Tondi et al. 2012a). Furthermore, tannins are known for their natural biocide activity (Sen et al. 2009) even if their efficacy decreases after polymerization (Thevenon et al. 2009).

The idea of using tannin as wood preservatives has been known for three decades (Laks et al. 1988), and it was successively pursued by several research groups (Yamaguchi and
Okuda 1998; Taylor et al. 2006; Tascioglu et al. 2012) in the following years. A significant breakthrough in the chemistry of flavonoid tannins was that their condensation reactions occurred with similar extent as phenol and resorcinol (Pizzi 1980; Pichelin et al. 1999), and therefore, it was possible to oppose the long-standing leaching problem of tannin in the wood preservation field and hence raise this approach to a new level.

The technology uses the polymerization of tannins and consists in infiltrating the activated oligomers of flavonoid in the wood with a successive in situ polymerization catalysed by heat (Thevenon et al. 2010). This can also be obtained in the presence of an active ingredient such as boric acid. Such associations allow combining the effects of both ingredients, using boric acid at a very low level and observe the restrictions on the use of boron compounds (2008/58/EC 2008), avoid boric acid leaching and increase performances and service life of such treated timber (Obanda et al. 2008).

Original formulations based on tannin-boric acid synergy have shown outstanding preservation properties against biologic attack and fire and have also improved mechanical properties (Tondi et al. 2012b; Tondi et al. 2014). However, the tannin-based treatment does not improve significantly the weathering resistance (Tondi et al. 2012c). The tannin polymer indeed is rigid and dark, and these two conditions carry (i) to mechanical polymer cracking during the continuous dimensional changes occurring when the wood is exposed outdoors and (ii) to higher radical degradation due to light exposure (Tondi et al. 2013b).

The idea of adding other template components to the original formulation considers two different technological approaches: Firstly, an unreactive polyether such as polyethylene glycol (PEG) was added as "steric hindering" filler to decrease the amount of cross-links in the hardened network, and secondly, a polymerizable molecule such as caprolactam, which can polymerize to polyamides producing protein-like polymers, was added to actively participate to the synthesis of a more linear copolymer (Pizzi 1994). Both approaches were considered to enable the polymer to become more elastic and clearer with the objective of producing high-performance wood preservatives. Retentions, resistances against leaching and fire, dimensional stability and colour changes during natural and artificial weathering are described in this paper, and preliminary FT-IR and ${ }^{13} \mathrm{C}$-NMR investigations on the advanced tannin-based formulations are also presented.

\section{Materials and methods}

\subsection{Materials}

Mimosa (Acacia mearnsii de Wildt) tannin extract was supplied by Silva Chimica (Cuneo, Italy), while 
hexamethylenetetramine (hexamine), boric acid, sodium hydroxide, caprolactam ( $\varepsilon$-caprolactam) and polyethylene glycol 400 (PEG) were provided by Sigma-Aldrich. The scots pine (Pinus sylvestris L.) sapwoods were provided by two different sawmills of Kuchl (Austria).

\subsection{Impregnation method}

Scots pine samples of various dimensions were cut from stabilized sapwood portions and successively oven-dried at $103{ }^{\circ} \mathrm{C}$ until constant weight (Mo). All treatments were performed on anhydrous wood blocks using a single vacuum pressure impregnation: The cycles consisted of $30 \mathrm{~min}$ at $8 \mathrm{mbar}$ in a desiccator, the tannin-based wood preservative solution was then introduced and the pressure was slowly increased up to ambient pressure. The specimens were kept under the tannin-based solution for $24 \mathrm{~h}$. After the impregnation treatment, the treated wood samples were removed and blotted with filter paper. The weight of the wet samples was recorded $(\mathrm{Mw})$, and the wet $(\mathrm{Rw})$ and dry $(\mathrm{Rd})$ retentions of active ingredients (tannin, boric acid) were calculated based on the following (Eqs. 1 and 2).

$$
\begin{aligned}
& \mathrm{Rw}=\frac{(\mathrm{Mw}-\mathrm{Mo})}{\mathrm{V}} \\
& \mathrm{Rd}=\frac{(\mathrm{Md}-\mathrm{Mo})}{\mathrm{V}}
\end{aligned}
$$

In these equations, Mo is the anhydrous weight before treatment $(\mathrm{kg}), \mathrm{Mw}$ is the wet weight after treatment $(\mathrm{kg})$, $\mathrm{Md}$ is the anhydrous weight after treatment and resin hardening and $V$ is the volume of wood blocks $\left(\mathrm{m}^{3}\right)$. The retention of the single components was calculated multiplying the wet retention for the concentration by weight of Table 1 .

The treated specimens were kept $16 \mathrm{~h}$ in the oven at $103^{\circ} \mathrm{C}$ to allow the tannin resin to harden (Thevenon et al. 2010). The weight of the dry samples was further registered, and the impregnated wood blocks were then reconditioned at $20{ }^{\circ} \mathrm{C}$ and $65 \%$ RH until constant mass before testing.

The tannin formulations tested were prepared according to Table 1 and following the method reported by Tondi et al. (2013b), caprolactam and PEG being considered as additives.

\subsection{Leaching}

Twenty samples for each treatment of dimensions $50 \times 25 \times 15 \mathrm{~mm}(\mathrm{~L}, \mathrm{R}, \mathrm{T})$ underwent two leaching procedures: The first was done according to the directives of the NF X 41-569 (2014) by dipping the treated samples under water with continuous stirring with exchanging the water at 1,2, 4, 8,16 and $48 \mathrm{~h}$. The second leaching process was done according to EN 84 (1997), dipping the treated specimens in water and vacuum impregnated, followed with successive water exchange after 2, 26, 50, 74, 98, 122, 146, 170, 194 and $218 \mathrm{~h}$.

The tannin released was quantified with an UVspectrometer Spectroquant Nov. 60 from Merck measuring the absorbance of the leaching water at the wavelength of $340 \mathrm{~nm}$ in which tannin presents a maximum of absorption. The concentration of the solutions was then calculated according to the calibration curve obtained with solutions of known tannin concentration ( $\mathrm{pH}$ 9.0). Data were successively elaborated so that the sum of the released tannin was reported at each leaching step.

\subsection{Fire resistance}

Untreated, treated and leached samples of $50 \times 25 \times 15 \mathrm{~mm}^{3}$ $(\mathrm{L}, \mathrm{R}, \mathrm{T})$ were exposed to direct short time flame contact tests (Tondi et al. 2014). The samples were exposed to the blueroaring flame of the Bunsen burner (9-cm distance between the sample and the flame source). Ignition time, flame time and ember time were registered. Each formulation was tested five times, and the data were averaged.

\subsection{Dimensional stability}

Six treated samples per treatment with dimensions $10 \times 20 \times 20 \mathrm{~mm}^{3}(\mathrm{~L}, \mathrm{R}, \mathrm{T})$ were dried until anhydrous state and exposed to constantly increasing humidity conditions for 1 week for each step. The radial and tangential dimension measurements were collected at $20^{\circ} \mathrm{C}$ with relative humidity of $0,10,20,30,40,50,60,70,80,90$ and $95 \%$. Untreated sapwood pine samples were used as controls. The dimensions were taken for every sample and reported as percentage increase before averaging.
Table 1 Percentage by weight of substances used for the preparation of the tannin-based wood preservatives

\begin{tabular}{lclllll}
\hline Formulation & $\begin{array}{l}\text { Tannin } \\
(\%)\end{array}$ & $\begin{array}{l}\text { Boric acid } \\
(\%)\end{array}$ & $\begin{array}{l}\text { Hexamine } \\
(\%)\end{array}$ & $\begin{array}{l}\mathrm{NaOH} \\
(\%)\end{array}$ & $\begin{array}{l}\text { Additive } \\
(\%)\end{array}$ & $\begin{array}{l}\text { Water } \\
(\%)\end{array}$ \\
\hline Tannin-boron 10\% & 9.73 & 0.49 & 0.58 & 0.49 & - & 88.72 \\
Tannin-boron 20\% & 19.12 & 0.96 & 1.15 & 0.96 & - & 77.82 \\
Tannin-caprolactam-boron & 8.14 & 0.41 & 0.49 & 0.41 & 15.56 & 75.01 \\
Tannin-PEG-boron & 9.72 & 0.49 & 0.58 & 0.49 & 19.41 & 69.34 \\
\hline
\end{tabular}




\subsection{Weathering}

Series of five samples of treated and untreated scots pine sample of dimensions $70 \times 50 \times 20 \mathrm{~mm}^{3}(\mathrm{~L}, \mathrm{R}, \mathrm{T})$ were exposed to artificial and natural weathering.

The colour of the surface was monitored with the Mercury 2000 spectrophotometer (Datacolor) after regular intervals of exposure. Six measurements (at defined positions) for each sample were recorded. The diameter of the spotlight used for measurement was $11 \mathrm{~mm}$. The wood colour was determined according to the CIELAB space with CIE standard illuminates D65 and a $10^{\circ}$ standard observer.

\subsubsection{Artificial QUV}

The simulated weathering was carried out in a QUV/spray accelerated weathering tester (Q-Panel Lab Products Cleveland, USA) according to the guidelines of EN 927-6 (2006).

The exposure cycles started with a condensation phase (24 h), followed by short intervals of UV light $(2.5 \mathrm{~h})$ with UVA-430 lamps and water spraying $(0.5 \mathrm{~h})$. The duration of the artificial weathering test was $1008 \mathrm{~h}$. The evaluation of the colour of the samples was carried out at $0,168,336,504,672$, 840 and $1008 \mathrm{~h}$ in six points per sample and averaged.

\subsubsection{Natural weathering}

The natural weathering tests were done fixing the untreated and the tannin-treated specimens in a $45^{\circ}$ grid located in Kuchl (Austria) and exposed to south for $2016 \mathrm{~h}$ of weathering (between 16 September 2013 and 9 December 2013). The evaluation of the colour of the samples was carried out at $0,168,504,672,1008,1512$ and $2016 \mathrm{~h}$ in six points per sample and averaged.

\subsection{FT-IR analysis}

Polymers of tannin-hexamine and the components of the advanced formulations were prepared as follows: Thirty grams of tannin-hexamine solution $30 \%$ at $\mathrm{pH} 9.0$ was prepared and divided into three test tubes: one reference and two tubes were added $6 \mathrm{~g}$ of solid caprolactam and PEG, respectively. The three test tubes were manually mixed until homogeneous and sealed before being exposed to $103{ }^{\circ} \mathrm{C}$ for $24 \mathrm{~h}$. The three formulations presented viscous liquid/solid, and therefore, a few milligrams of each test tube was removed and dried in a petri dish at $60{ }^{\circ} \mathrm{C}$ for $4 \mathrm{~h}$. The three solids, the PEG and the caprolactam were scanned three times in a PerkinElmer Frontier FT-IR spectrometer between 4000 and $650 \mathrm{~cm}^{-1}$, with a resolution of $4 \mathrm{~cm}^{-1}$ and 32 scans. The obtained spectra were averaged, baseline corrected and normalized with Unscrambler X version 10.3 software by Camo (Oslo,
Norway). The principal component analysis was carried out using the NIPALS algorithm.

\section{$2.8{ }^{13} \mathrm{C}-\mathrm{NMR}$ analysis}

The polymers of tannin-hexamine and tannin-hexamine caprolactam prepared in the same way as previously described for the FT-IR analysis were measured at $25^{\circ} \mathrm{C}$ with an Ascend 500 NMR spectrometer by Bruker (Germany). The instrument settings were optimized for carbon $\left({ }^{13} \mathrm{C}\right)$ detection, and the measurements were performed with $62.90 \mathrm{MHz}$ for 1000 transients and relaxation time of $5 \mathrm{~s}$.

\section{Results}

\subsection{Retentions}

The wood preservative uptake is possibly one of the most important parameters to be investigated when a wood preservative is tested. It was observed that the scots pine samples were generally easily impregnable with low tannin content formulations (Fig. 1a, b).

Significantly lower liquid uptakes were registered for the samples $70 \times 50 \times 20 \mathrm{~mm}^{3}$ when $20 \%$ tannin solutions were applied. The effect of the sample dimensions is observed also for the $10 \%$ tannin solution but to a much lower extent. The presence of caprolactam does not significantly modify the liquid uptake, but the formulations containing PEG showed a generally lower penetrability due to the increase of viscosity of these formulations.

Conversely, the solid uptake was considerably lower for the samples treated with $10 \%$ tannin solution and no further additives. The presence of caprolactam and PEG enhances the amount of solid ingredients in wood to the level achieved with the $20 \%$ tannin formulation.

These observations suggest that the presence of additives allows a similar penetration of the wooden pieces to the $10 \%$ tannin formulation and simultaneously enhances the amount of solid preservative in the structure to the level achieved with $20 \%$ tannin preservatives.

Indeed, the samples treated with PEG register high standard deviations because the surface presents an observable viscous layer which becomes much thicker as soon as the samples are kept under water for a while. This PEG gelatinous skin is probably due to the accumulation of unpenetrated PEG, and therefore, also the analysis of the results has to take into account this behaviour. According to the mean values, it is possible to calculate the tannin and the boron content in $\mathrm{kg} /$ $\mathrm{m}^{3}$ of wood (Table 2).

These data are affected by very high standard deviations because they come from samples of different dimensions and because the end-grain surfaces were different. However, much 
a

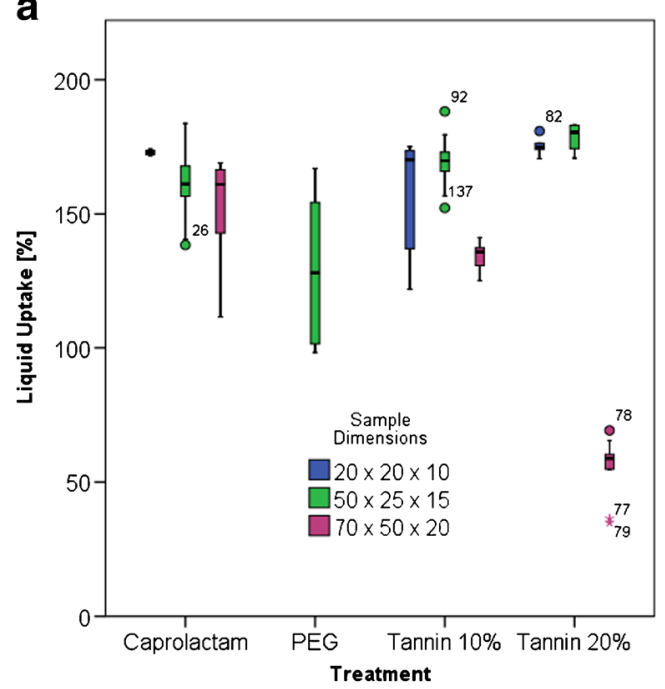

b

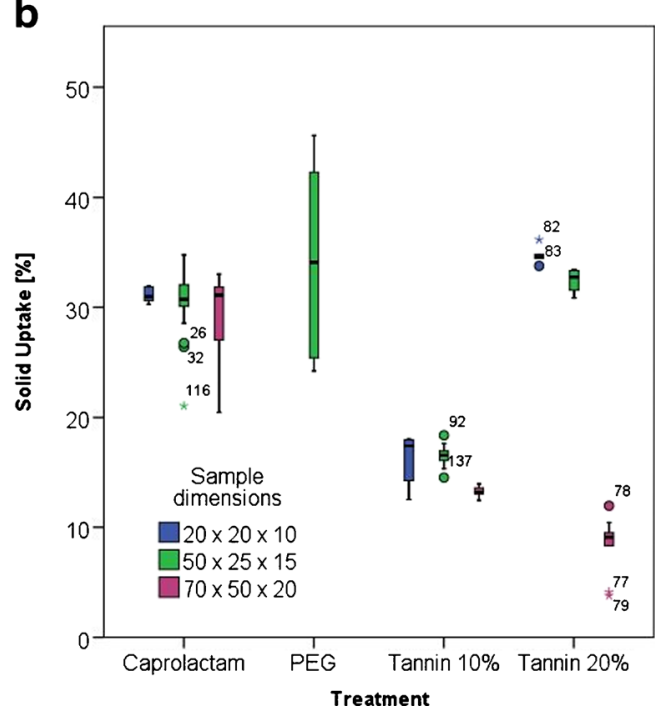

Fig. 1 Retention of the tannin-based formulations against different sample dimensions during the impregnation process: a liquid uptake and $\mathbf{b}$ solid uptake

higher variances are registered for the samples treated with tannin 20\% and PEG-modified formulations.

It can be seen that the advanced formulations have a lower tannin and boron content. Hence, it is expected that such treated wood would have a lower biological resistance, unless boron is very efficiently maintained into the wood (during leaching).

The study of the biological properties of these advanced formulations is discussed in the second part of this work $(\mathrm{Hu}$ et al. 2016).

\subsection{Leaching behaviour}

The resistance to leaching of the advanced formulations was investigated and compared to that of standard formulations (10 and 20\% tannin without additives).

In Fig. 2a, b, the amount of leached tannin according to the NF X 41-569 and EN 84 are reported. The results obtained for the 10 and $20 \%$ tannin-treated timber confirm the previous tests where only a restrained amount of tannin was leached out (Tondi et al. 2012b). The samples treated with the two advanced formulations, with PEG and caprolactam, show even lower decrease of leached tannin. The tannin loss is always lower than $20 \%$ of the original tannin content in the sample when applying the NF X 41-569 procedure. This tendency is confirmed also when using the notoriously drastic EN 84 procedure, for which one the tannin is leached out for less than $15 \%$ related to its original amount.

Furthermore, it can also be observed that the amount of tannin leached is similar comparing the two leaching treatment after specific time. This means that both leaching methods are able to leach out a similar amount of tannin suggesting that only the non-reacted tannin oligomers can easily leach out, while the cross-linked fractions stay in wood also when forceful leaching process occurs.

The loss of tannin during leaching is limited for PEGtreated samples. This phenomenon is mostly due to the protective effect of PEG layer which is found all over the wood surface. The appearance of the specimens at the end of the leaching presents a thick gelatinous film of swelled PEG that made the samples unable to be handled. Due to this drawback, the PEG formulation was not further investigated.

The caprolactam-added formulations also showed outstanding leaching resistance. The leaching of tannin for the sample treated with this formulation is around $40 \%$ less than that shown by the samples treated with the $10 \%$ tannin standard formulation.
Table 2 Retention of tannin and boron in the different tanninbased formulations

\begin{tabular}{lllll}
\hline Formulation & $\begin{array}{l}\text { Wet retention } \\
\left(\mathrm{kg} / \mathrm{m}^{3}\right)(\mathrm{SD})\end{array}$ & $\begin{array}{l}\text { Dry retention } \\
\left(\mathrm{kg} / \mathrm{m}^{3}\right)(\mathrm{SD})\end{array}$ & $\begin{array}{l}\text { Tannin content } \\
\left(\mathrm{kg} / \mathrm{m}^{3}\right)\end{array}$ & $\begin{array}{l}\text { Boron content } \\
\left(\mathrm{kg} / \mathrm{m}^{3}\right)\end{array}$ \\
\hline Tannin-boron 10\% & $630.5(74.1)$ & $62.2(7.4)$ & 61.3 & 0.53 \\
Tannin-boron 20\% & $412.3(238.5)$ & $75.5(52.4)$ & 78.8 & 0.69 \\
Caprolactam-tannin-boron & $644.5(42.7)$ & $122.3(9.1)$ & 52.5 & 0.46 \\
PEG-tannin-boron & $517.0(109.3)$ & $136.7(34.7)$ & 50.2 & 0.44 \\
\hline
\end{tabular}

$S D$ standard deviation 


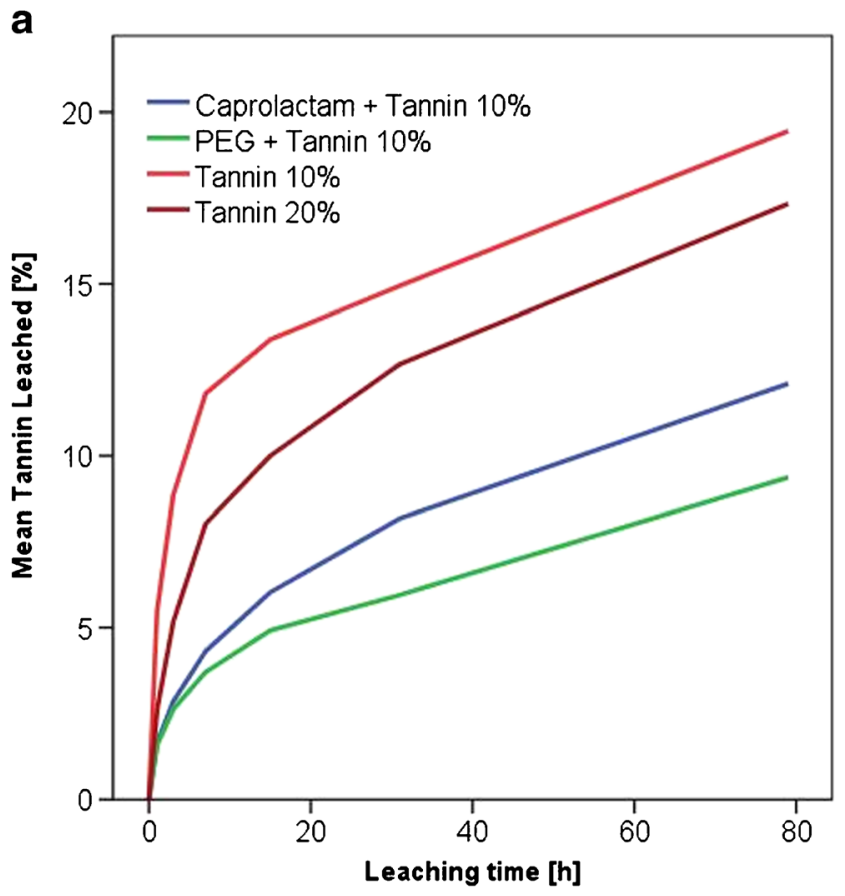

b

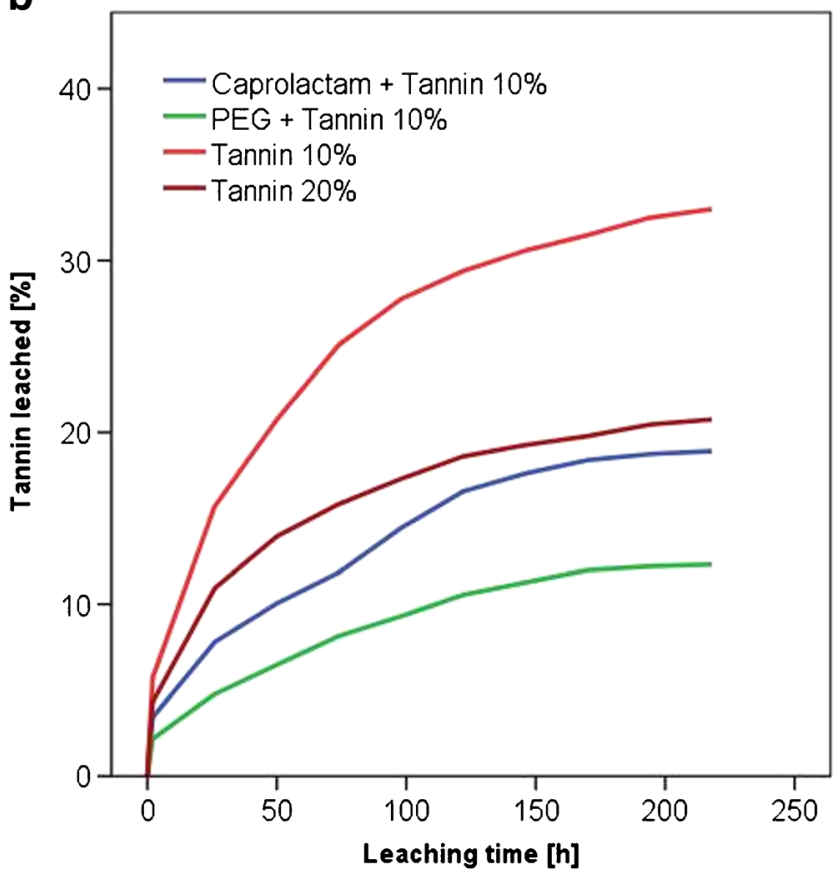

Fig. 2 Percentage of total tannin released during the leaching process: a NF X 41-569 and b EN 84

In particular, in the latest leaching days of the EN 84 procedure, the amount of tannin leached out is very low, and it represents a threshold for the maximum leaching of tannin, suggesting that no further loss will occur. In addition, the fact that the samples treated with caprolactam show a more homogeneous colour distribution on the surface in comparison with the standard tannin formulation allows to consider that this advanced formulation is more suitable for active ingredient retentions and thus for outdoor exposures.

\subsection{Fire resistance}

The fire behaviour of the formulation treated with caprolactam is compared with the values of the standard formulations, and results are reported in Table 3.

It looks evident that the addition of caprolactam decreases the fire resistance of the tannin-boron standard formulation even if a mild improvement is still observed when the formulation is compared to untreated scots pine.

\subsection{Dimensional stability}

The dimensional stability of the treated samples is another important parameter for evaluating the stresses occurring in wood during weathering. One of the main hypothesis made for explaining the low weathering resistance of the standard tannin formulation was their highly rigid behaviour that led to polymer cracks during dimensional changes induced by weathering.

In Fig. 3, the radial and tangential dimensional changes are depicted.

The two figures show that the presence of caprolactam in the formulation decreases the affinity of the wood specimens for water, and therefore, lower swellings in radial and tangential direction are observed. A certain contribution to this tendency is that the amount of the "hydrophilic" tannin uptake is slightly decreased. However, it cannot be excluded that the higher amount of solid preservative up-taken creates a more resistant polymer by increasing the tensions inside these samples. Hence, it is expected that during outdoor exposures, the

Table 3 Ignition, flame and ember time of caprolactam tannin-treated wood in comparison with the "standard" formulations

\begin{tabular}{lcll}
\hline Formulation & $\begin{array}{c}\text { Ignition } \\
\text { time (s) }\end{array}$ & $\begin{array}{l}\text { Flame } \\
\text { time (s) }\end{array}$ & $\begin{array}{l}\text { Ember } \\
\text { time (min) }\end{array}$ \\
\hline Untreated & 8.6 & 192 & 4.9 \\
Tannin-boron 10\% & $75^{1}$ & $35^{1}$ & $2.5^{\mathrm{a}}$ \\
Tannin-boron 20\% & $110^{2}$ & $15^{2}$ & $0.9^{\mathrm{b}}$ \\
Caprolactam-tannin-boron & 12.7 & 185 & 3.9 \\
$\begin{array}{l}\text { Caprolactam-tannin-boron } \\
\quad \text { leached }\end{array}$ & 12.5 & 180 & 4.1 \\
$\quad$ NF X 41-569) & & & \\
Caprolactam-tannin-boron & 12.8 & 178 & 4.1 \\
$\quad$ (leached & & & \\
$\quad$ EN 84) & & & \\
\hline
\end{tabular}

${ }^{\text {a }}$ Tondi et al. (2012a)

${ }^{\mathrm{b}}$ Tondi et al. (2013b) 

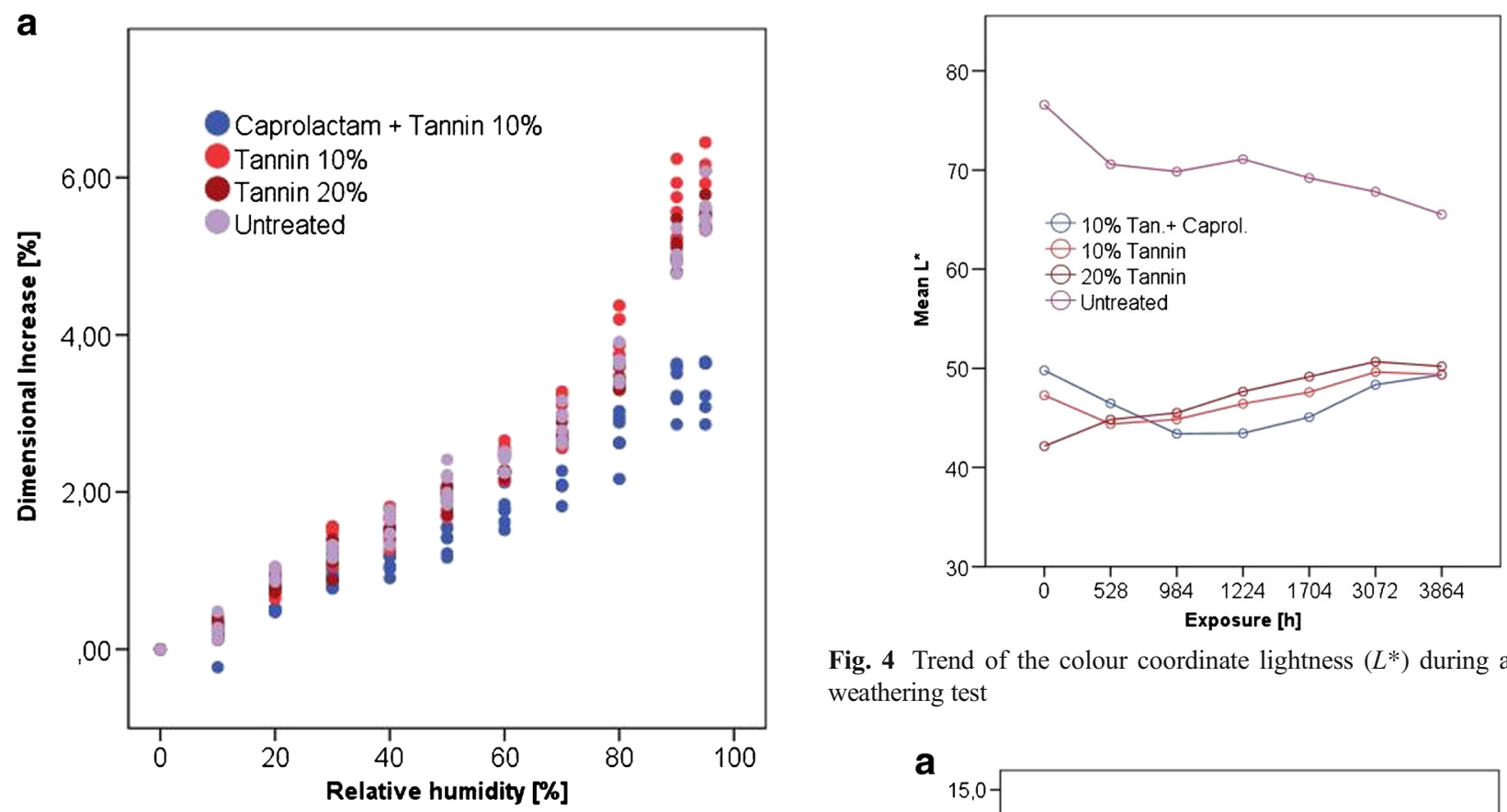

Fig. 4 Trend of the colour coordinate lightness $\left(L^{*}\right)$ during artificial weathering test

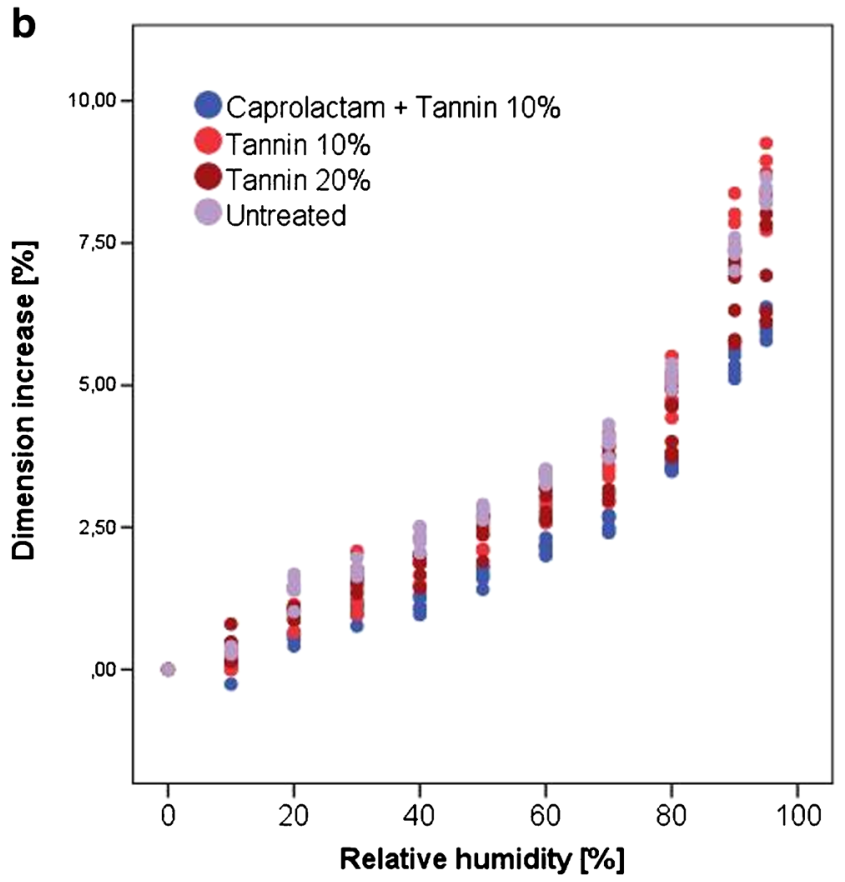

Fig. 3 Dimensional swelling of untreated, 10 and 20\% tannin-treated scots pine specimens compared with tannin-caprolactam-treated samples under different $\mathrm{RH}$ conditions at $20^{\circ} \mathrm{C}$. a Radial swelling and b tangential swelling

caprolactam-tannin-treated samples will better prevent the swelling/shrinkage strain producing a more stable material in which reduced amount and intensity of cracks will be observed (Hansmann et al. 2006). The better distribution of the wood preservative in the material suggests also that its properties will resist unchanged also in a long run weathering exposure.

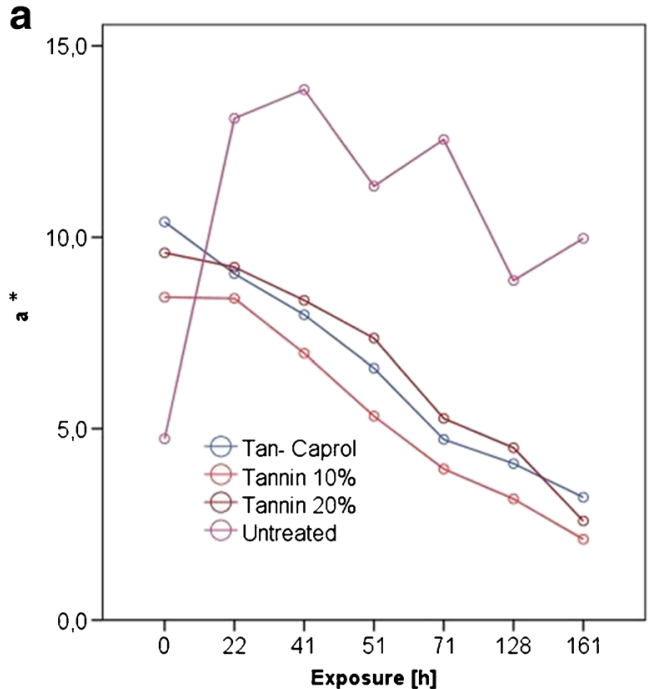

b

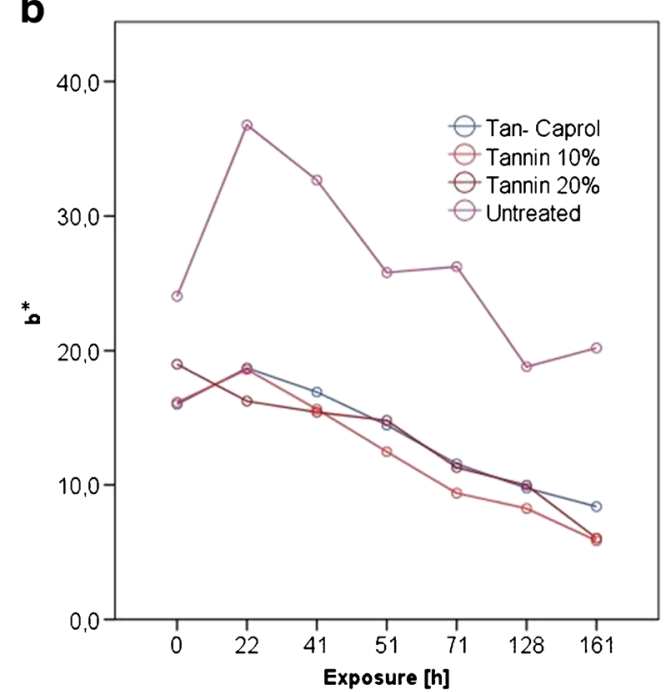

Fig. 5 Trend of the colour coordinate a $a^{*}$ and $\mathbf{b} b^{*}$ during artificial weathering test 


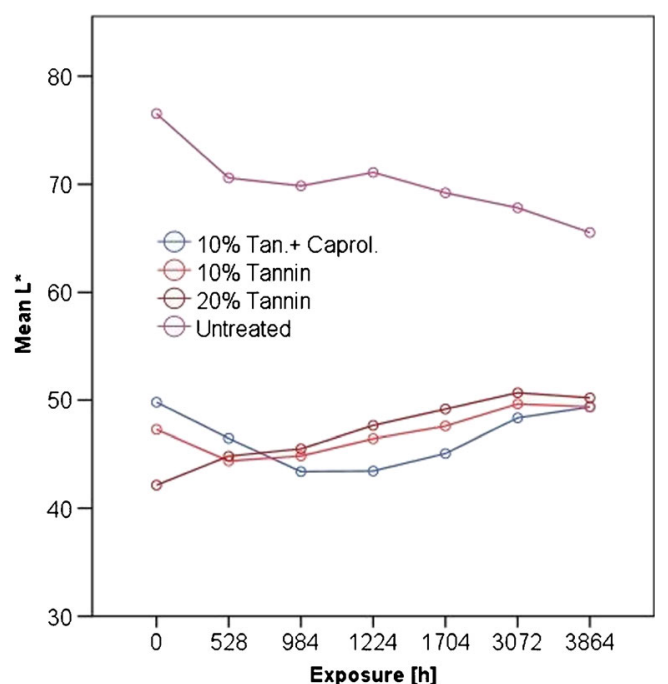

Fig. 6 Trend of the colour coordinate $L^{*}$ during natural weathering test

\subsection{Weathering}

Notwithstanding the considerable advantage carried by the addition of caprolactam, the key tests for the evaluation of these wood preservatives are undoubtedly the weathering tests.

The artificial weathering tests were followed monitoring the colour of the surface after different time lapses. According to our previous work, $L^{*}$ is the more appropriate parameter to describe the effects of weathering (Tondi et al. 2013b). The evolution of this parameter during weathering is given in Fig. 4.
It can be observed that at the beginning of the experiment, the caprolactam-modified samples have a slightly lighter colour than the other tannin-treated specimens. After 168-h exposure, the colour turns darker and becomes very similar to that of the standard formulations. Then, the greying begins, and it can be observed that the caprolactam-modified samples converge also to the grey level of untreated wood but significantly more slowly than the samples treated with the standard formulations.

These observations suggest that the polymer of tannin containing caprolactam resists the weathering better than the standard formulation even if it still have the tendency to reach the grey level of the untreated specimens.

The $a^{*}$ and the $b^{*}$ values, the yellow-blue and the greenred components of the colour, respectively, do not significantly change between the advanced tannin formulations and the standard ones (Fig. 5a, b).

In particular, the component $a^{*}$ shows a continuous fading of the red turning to greenish, and the $b^{*}$ component gets also a negative slope underlining that the colour tends to turn blue. The general aspect of the surface tends to grey; however, the caprolactam-modified formulations maintain a lower value of $L^{*}$ for longer time, meaning that the tannins remain longer in the wood samples.

The natural weathering shows the same trend (Fig. 6) confirming the retention of the tannin polymer into the wood samples.

It has to been noticed that the trend observed for the weathering test is repeated also in the natural weathering, with the only difference of showing a degradation of the advanced

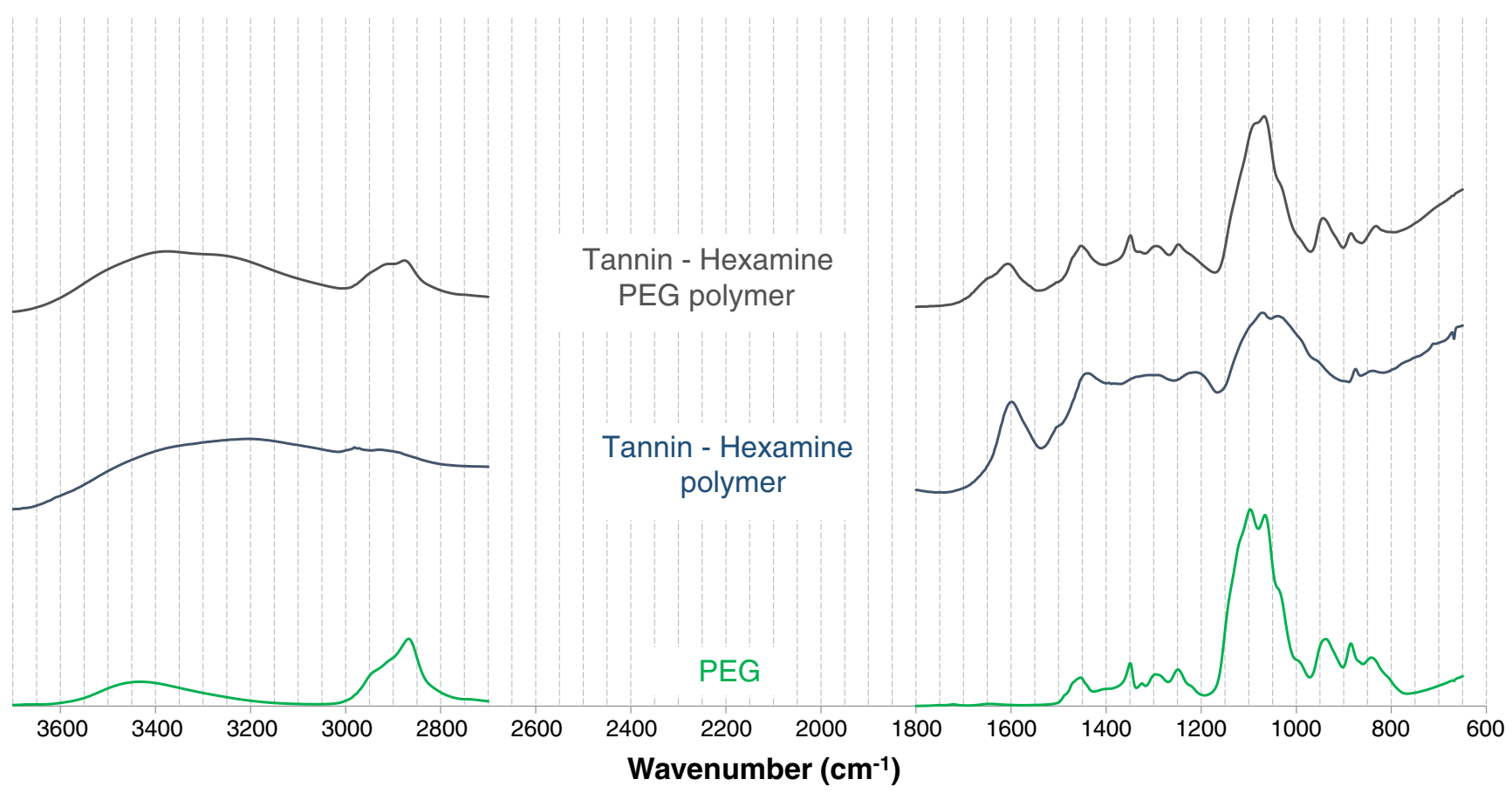

Fig. 7 FT-IR spectra of the tannin-hexamine-PEG blend compared with the tannin-hexamine polymer and the PEG 


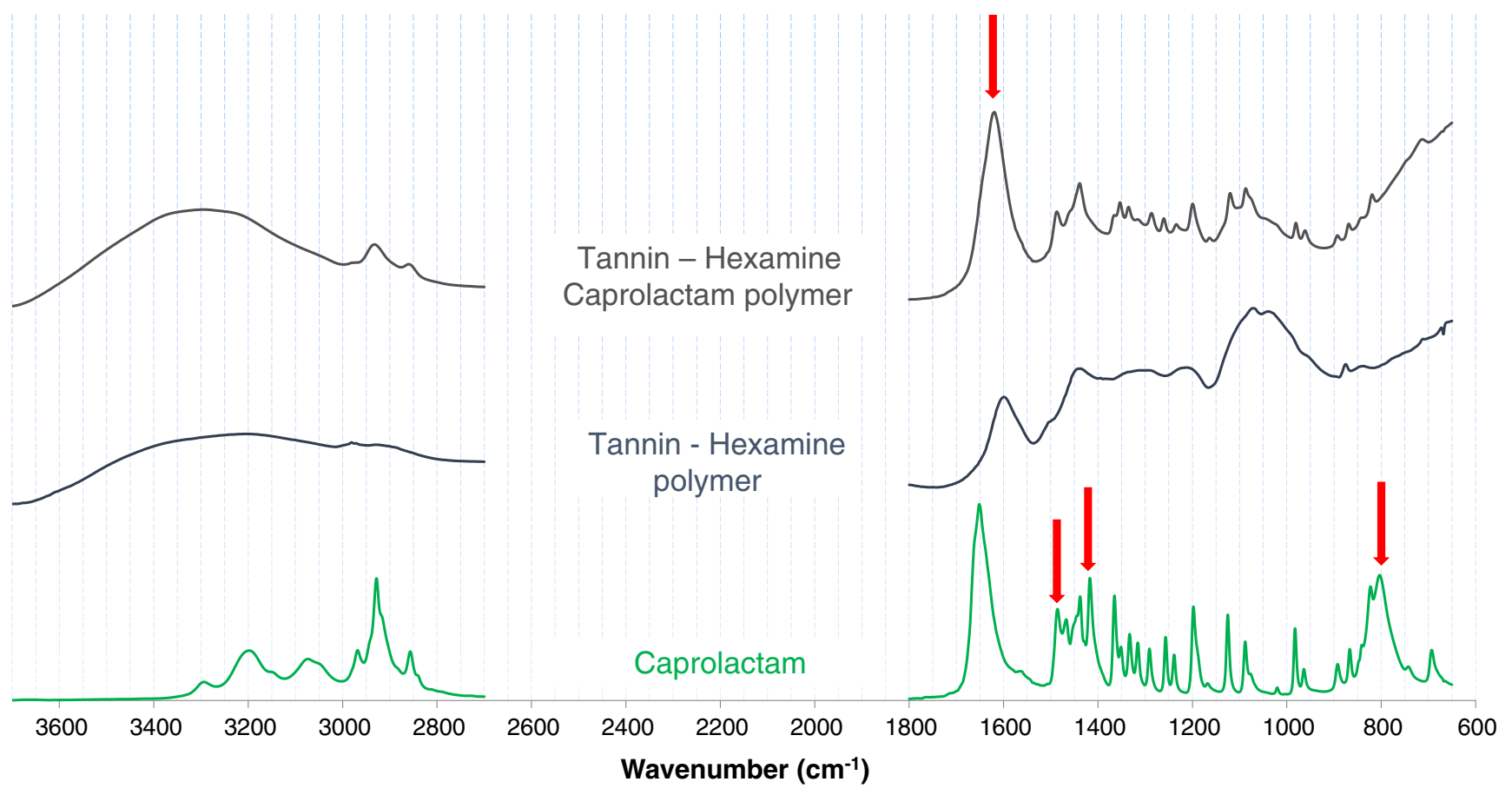

Fig. 8 FT-IR spectra of the tannin-hexamine-caprolactam blend compared with the tannin-hexamine polymer and the caprolactam

formulation very similar to the standard formulations. This decrease of lightness occurs in the final part of the exposure which coincides with the period after several days of snow.

The cold temperatures of the period of exposure suggest internal stress of the wood much higher than during the dimensional stability test because the daily cycle of ice formation/melting undergoes the wood to higher solicitations, able to break down also the tannin-caprolactam copolymers.

\subsection{FT-IR and ${ }^{13} \mathrm{C}-\mathrm{NMR}$ analysis}

In the following Figs. 7 and 8, the FT-IR spectra of the two advanced formulations are reported and compared with the standard tannin-hexamine polymer (Schnabel et al. 2014) and the pure additives.

It can be observed in both figures that almost all the vibrational signals of the advanced formulations are obtainable by

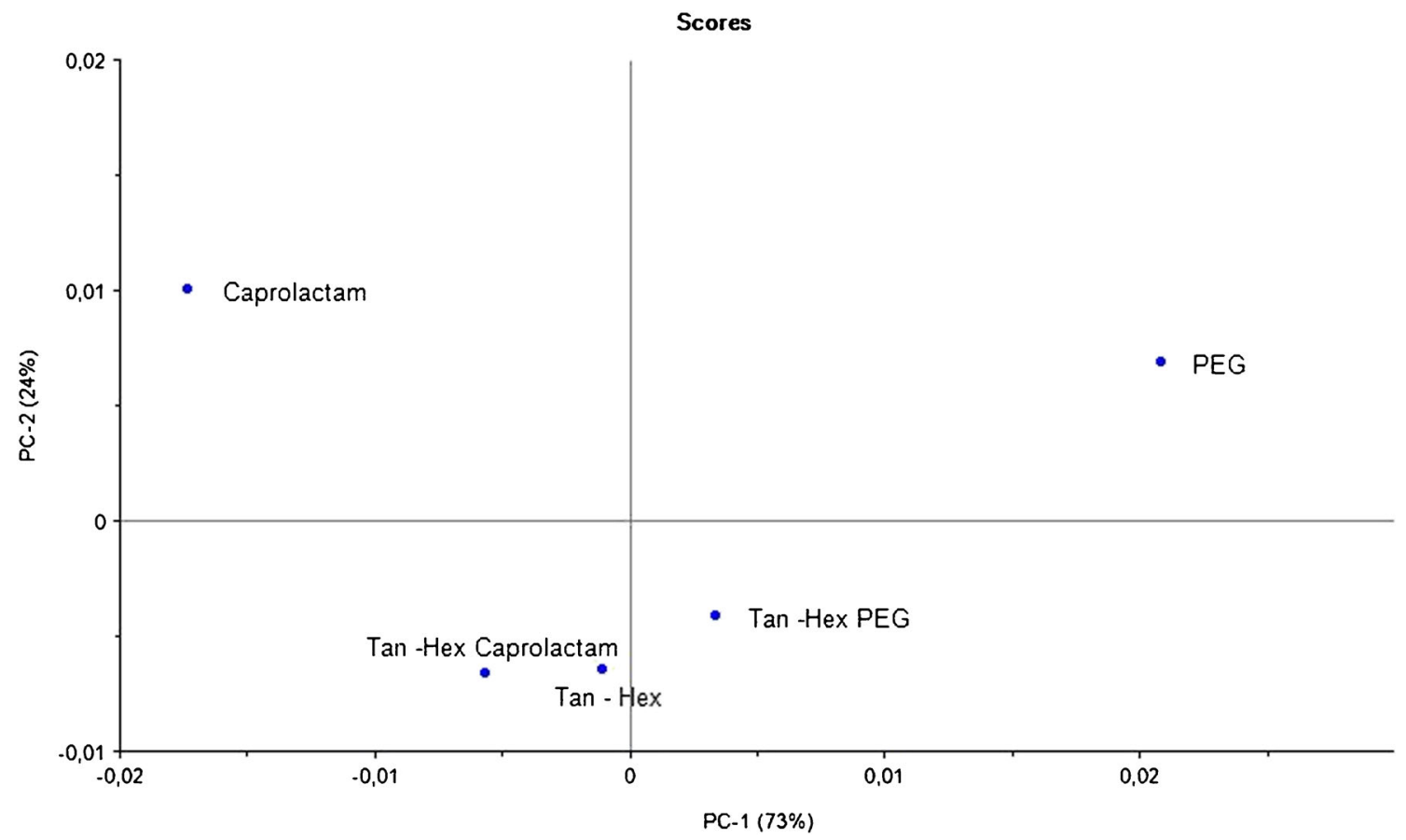

Fig. 9 Principal component analysis of the five spectra 


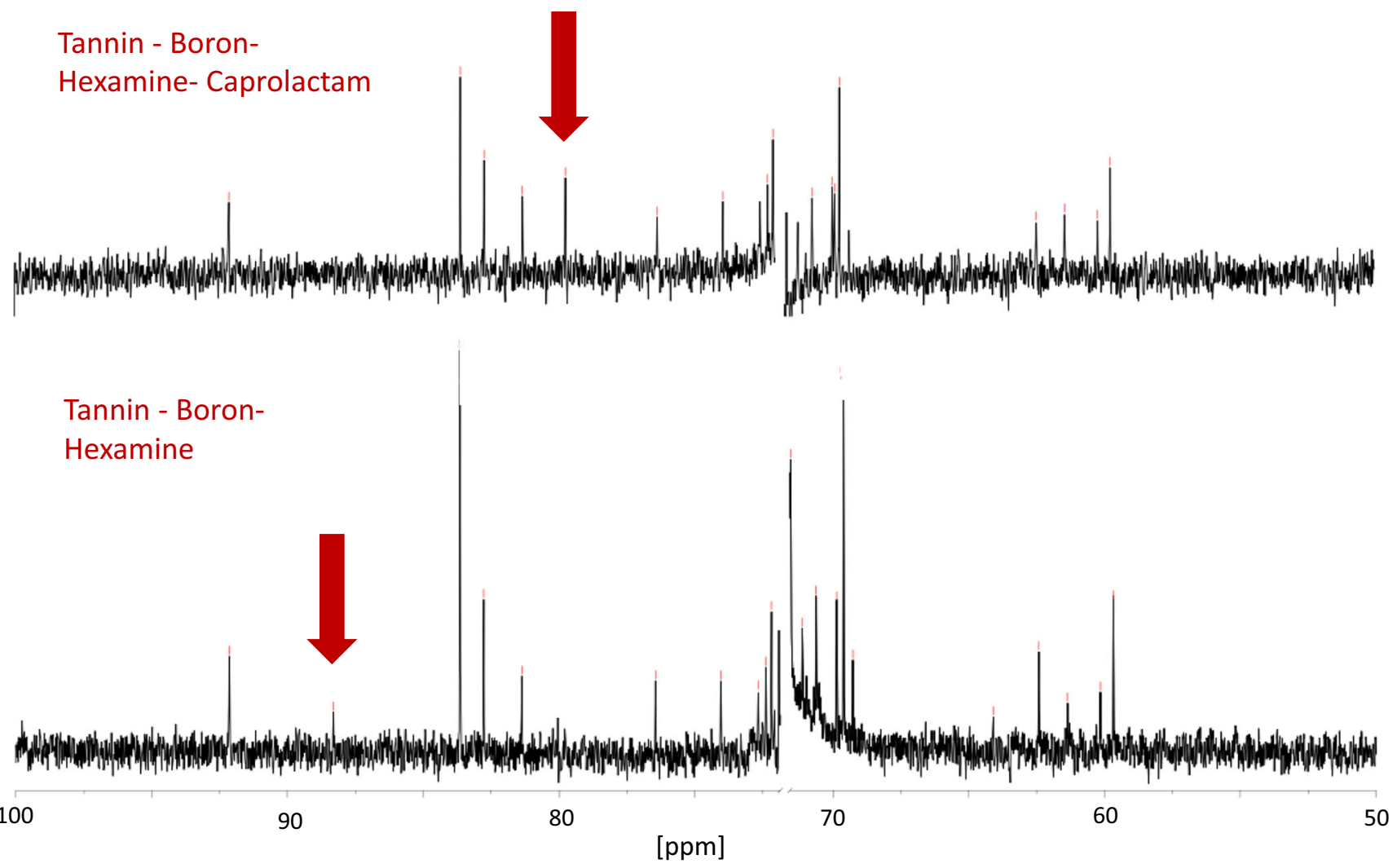

Fig. 10 C-NMR of tannin-boron-hexamine and tannin-boron-hexamine-caprolactam polymers

superposition of the tannin-hexamine polymer and the pure additive. In the case of PEG, no new signal is observable or disappearing. It seems that no copolymerization between PEG and tannin-hexamine occurs. Conversely, in the formulation containing caprolactam, there are a few differences that have to be noticed. The signal of $\mathrm{C}=\mathrm{O}$ stretching of amide is shifted from 1650 to $1620 \mathrm{~cm}^{-1}$, while the signals at 1560,1415 and $820 \mathrm{~cm}^{-1}$ are not observed in the polymer (see arrows). However, the attribution of the signals is not easy, and therefore, the principal component analysis was done in order to extrapolate the maximum of the information. In Fig. 9, the two principal components ( $\mathrm{PC} 1$ and $\mathrm{PC} 2$ ) are represented in a Cartesian graphic.

The main principal component $(\mathrm{PC} 1=73 \%$ ) classifies the chemical aspect of the formulations in three main classes: (i) the amides, (ii) the polyether and (iii) the flavonoids. The two advanced formulations are correctly located between the tannin-hexamine polymer and the respective pure additive. The second principal component $(\mathrm{PC} 2=24 \%$ ) distinguishes between the tannin polymer and the pure bases, and it considers the formulation tannin-hexamine caprolactam very similar to the one of tannin-hexamine, while the tannin-hexaminePEG also in this case shows intermediate values between the tannin-hexamine and the pure PEG. Further investigation with ${ }^{13} \mathrm{C}$-NMR was required for a better understanding of the chemistry of tannin-hexamine-caprolactam, and the spectra of the tannin-hexamine and tannin-hexamine-caprolactam are presented in Fig. 10.

It can be observed that in the region around $79.38 \mathrm{ppm}$, a new signal occurs. This signal was not present in the spectra of caprolactam, and therefore, it belongs to a carbon with new surroundings. This signal belongs to a new species $\mathrm{R}-\mathrm{CH}_{2}-$ $\mathrm{O}-$, and hence, a new ether bond occurs. This evidence confirms that a new covalent copolymer is formed between caprolactam and the tannin-hexamine. It has to be noticed that a small signal at 88.31 disappears when caprolactam is added. This signal can be attributed to carbons between two electronegative atoms, and in particular, a $-\mathrm{O}-\mathrm{CH}_{2}-\mathrm{O}-$ moiety would be the more probable. This could be attributed to the presence of traces of consecutive methylene ether bridges.

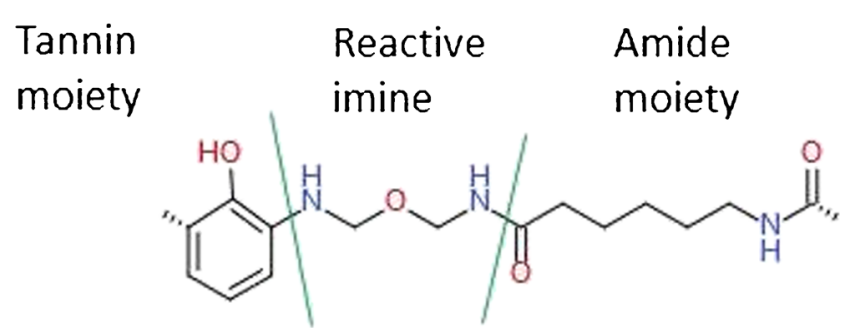

Fig. 11 Possible polymer structure of a tannin-hexamine-caprolactam polymer 


\section{Discussion}

The advanced tannin-boron formulations have presented opposite behaviour. The formulation in which PEG was added presented average wet retentions and high solid uptake with very high standard deviations. This meant that the formulation was not able to penetrate into the wood and that most of the solid was accumulated on the surface. This drawback became very important when the samples were immersed in water. The unpenetrated PEG took up water and formed a transparent gelatinous layer of a few millimetres.

The FT-IR confirmed that there was no chemical linkage between the PEG and the tannin-hexamine polymer.

Completely different results were observed for the caprolactam-added formulations. High wet and dry retentions as well as contained standard deviation suggested a very good penetration of the wood preservative and a homogeneous distribution of the latter. The positive leaching resistance and the improved dimensional stability suggested that the caprolactam intimately connect with the tannin polymer and that it participated in rendering the surface less penetrable by water even when the leaching process applied was very intense (EN 84). These improvements were reflected also in the weathering which presented a considerable enhancement of the outdoor durability of these formulations. As expected, the addition of an organic substance decreased the performances against fire of the formulation.

The FT-IR analysis of the caprolactam formulations presented some modifications which mostly consisted in signal loss. This can be interpreted like a polymer formation with the overlapping of many bands. The PC analysis showed a very similar value of PC2 with the original tannin-hexamine which might imply a certain degree of inclusion in the polymer. The ${ }^{13} \mathrm{C}$-NMR investigation confirmed that new covalent bondings are occurring when caprolactam is added to the tannin-hexamine formulation.

According to the literature, caprolactam in water evolves rapidly to aminocaproic acid, and in alkaline environment, the process of polymerization can occur as well especially if catalysed by temperature (Ritz et al. 2005). The inclusion of the monomeric aminocaproic acid or its oligomers in the tannin-hexamine network can be figured out in many ways. According to the signal of $\mathrm{R}-\mathrm{CH}_{2}-\mathrm{O}$, the more probable hypothesis is that the reactive imines produced from hexamine in alkaline environment react with the carboxylic group of the caprolactam (Pichelin et al. 1999). Here, a possible polymer structure is observed (Fig. 11).

The phenolic part on the left side represents the tannin; the amino ether shows the interconnection due to the reactive imines, and the amide from the aminocaproic acid shows the continuation of the polymer.

\section{Conclusions}

The use of PEG and caprolactam to increase the weathering resistance of the tannin polymer has led to interesting results. It was observed that even if the impregnation treatment was possible for both the additives, the PEG-added formulation developed a gelatinous surface layer when dipped in water. This feature has excluded the use of PEG-tannin formulation for outdoor applications. Conversely, the advanced tannincaprolactam formulation gave positive results that can be summarized in improved leaching resistance, improved dimensional stability and improved weathering resistance compared to the standard tannin-boron formulations. These formulations presented also very satisfactory retentions and enhanced fire properties compared with untreated wood. The FT-IR investigations of the two advanced formulations have confirmed that the PEG does not covalently bind with the tannin polymer, while some evidence of polymerization are observed for the caprolactam-added formulations which were confirmed by ${ }^{13} \mathrm{C}-\mathrm{NMR}$. The interesting results obtained including caprolactam in the tannin-hexamine copolymer offer the opportunity to produce environmentally friendly, high-performing solutions in which other natural polyamides like proteins can be suited for the protection of wood.

Acknowledgements Open access funding provided by FH Salzburg University of Applied Sciences. The authors gratefully acknowledge the support of the ERA-Net WoodWisdom program for the project "BIOCOPOL-Enhancing wood durability and physical properties through innovative bio-based sustainable treatments."

Dr. Jinbo HU acknowledges to the supports, which are provided by Scientific Research Fund of Hunan Provincial Education Department (16B281) and Scientific Research Foundation for High-level Personnel of Central South University of Forestry and Technology(2015YJ023) in China.

\section{Compliance with ethical standards}

Funding The study was financed for one part by the European Union with the ERA-Net WoodWisdom program and namely to the project "BIOCOPOL - Enhancing wood durability and physical properties through innovative bio-based sustainable treatments."

Open Access This article is distributed under the terms of the Creative Commons Attribution 4.0 International License (http:// creativecommons.org/licenses/by/4.0/), which permits unrestricted use, distribution, and reproduction in any medium, provided you give appropriate credit to the original author(s) and the source, provide a link to the Creative Commons license, and indicate if changes were made.

\section{References}

2003/2/EC (2003) Restrictions on the marketing and use of arsenic (tenth adaptation to technical progress to Council Directive 76/769/EEC) European directive 2003/2/EC, 06/01/2003 
2008/58/EC (2008) Amendment of 67/548/EEC on the approximation of the laws, regulations and administrative provisions relating to the classification, packaging and labelling of dangerous substances

2011/71/EU (2011) Include creosote as an active substance in Annex I of the 98/8/EC. European directive 2011/71/EU, 26/07/2011

98/8/EC (1998) Placing on the market of biocidal products. European directive 98/8/EC, 16/02/1998

EN 84 (1997) Wood preservatives, accelerated ageing of treated wood prior to biological testing, Leaching procedure. European Committee for Standardization

EN 927-6 (2006) Paints and varnishes. Coating materials and coating systems for exterior wood. Exposure of wood coatings to artificial weathering using fluorescent UV lamps and water. European Committee for Standardization

Evans P (2003) Emerging technologies in wood protection. Forest Prod J $53: 14-22$

Evans P, Wingate-Hill R, Cunningham RB (2009) Wax and oil emulsion additives: how effective are they at improving the performance of preservative-treated wood? Forest Prod J 59:66-70

Hansmann C, Deka M, Wimmer R, Gindl W (2006) Artificial weathering of wood surface modified by melamine formaldehyde resins. Holz Roh Werkst 64:198-203

Hu J, Thevenon MF, Palanti S, Tondi G. (2016) Advanced tannin-boron formulations. Part 2: Biological properties (2016). Ann Forest Sci. Under review

Hyvönen A, Piltonen P, Niinimäki J (2006) Tall oil/water emulsions as water repellents for scots pine sapwood. Holz Roh Werkst 64:68-73

Laks PE, McKaig PA, Hemingway RW (1988) Flavonoid biocides: wood preservatives based on condensed tannins. Holzforschung 42:299 306

Lesar B, Humar M (2011) Use of wax emulsions for improvement of wood durability and sorption properties. Eur J Wood Wood Prod. 69:231-238

Mai C, Kües U, Militz H (2004) Biotechnology in the wood industry. Appl Microbiol Biot 63:477-494

Mazela B (2007) Fungicidal value of wood tar from pyrolysis of treated wood. Waste Manag 27:461-465

NF X 41-569 (2014) Wood preservatives-laboratory method for obtaining samples for analysis to measure losses by leaching into water or synthetic water-AFNOR

Nöel M, Fredon E, Mugel E, Masson D, Masson E, Delmotte L (2009a) Lactic acid/wood-based composite material. Part 1: synthesis and characterization. Bioresource Technol. 4711-4716

Nöel M, Fredon E, Mougel E, Masson E, Masson D (2009b) Lactic acid/wood-based composite material. Part 2: physical and mechanical performance. Bioresource Technol 100:4717-4722

Obanda ND, Shupe FT, Barnes MH (2008) Reducing leaching of boron based wood preservatives - a review of research. Bioresource Technol 99:7312-7322

Palanti S, Feci E, Torniai AM (2011) Comparison based on field tests of three low-environmental-impact wood treatments. Int Biodeter Biodegr 65:547-552

Pichelin F, Kamaun C, Pizzi A (1999) Hexamine hardener behaviour: effects on wood glueing, tannin and other wood adhesives. Holz Roh Werkst 57:305-313

Pizzi A (1980) Tannin-based adhesives. J Macromol Sci-Pol r 18:247315

Pizzi A (1994) Advanced wood adhesive technology. Dekker, New York

Polus-Ratajczak I, Mazela B (2004) The use of blood protein in wood preservatives. Holz Roh Werkst 62:181-183

Richardson B (1993) Wood preservation, 2nd edn. E \& FN Spon, Cambridge

Ritz J, Fuchs H, Kieczka H, Moran WC (2005) Caprolactam. Ulmann Encyclopedia of iIndustrial chemistry, 6th edn. Wiley, USA

Ruddick JNR (2011) Uhlig's corrosion handbook. Wiley-ECS, New Jersey
Schnabel T, Musso M, Tondi G (2014) Univariate and multivariate analysis of tannin-impregnated wood species using vibrational spectroscopy. Appl Spectrosc 68:488-494

Schultz TP, Nicholas DD, Preston AF (2007) A brief review of the past, present and future of wood preservation. Pest Manag Sci 63:784 788

Sen S, Tascioglu C, Trrak K (2009) Fixation, leachability, and decay resistance of wood treated with some commercial extracts and wood preservative salts. Int Biodeter Biodegr 63:135-141

Singh T, Singh AP (2012) A review on natural products as wood protectant. Wood Sci Technol 46:851-870

Tascioglu C, Yalcin M, De Troya T, Sivrikaya H (2012) Termiticidal properties of some wood and bark extracts used as wood preservatives. Bioresources 7:2960-2969

Taylor AM, Gartner BL, Morrell JJ, Tsunoda K (2006) Effects of heartwood extractive fractions of Thuja plicata and Chamaecyparis nootkatensis on wood degradation by termites or fungi. J Wood Sci 52:147-153

Temiz A, Alfredsen G, Eikenes M, Terzıev N (2008) Decay resistance of wood treated with boric acid and tall oil derivates. Bioresource Technol 99:2102-2106

Temiz A, Alma MH, Terziev N, Palanti S, Feci E (2010) Efficiency of bio-oil against wood destroying organisms. J Biobased Mater Bio 4: 317-323(7)

Thévenon MF, Pizzi A (2003) Polyborate ions influence on the durability of wood treated with the non-toxic protein borate preservatives. Holz Roh Werkst vol 61:457-464

Thevenon MF, Pizzi A, Haluk JP (1997) Non-toxic albumin and soja protein borates as ground-contact wood preservatives. Holz Roh Werkst 55:293-296

Thevenon MF, Tondi G, Pizzi A (2009) High performance tannin resinboron wood preservatives for outdoor end-uses. Eur J Wood Wood Prod. 67:89-93

Thevenon MF, Tondi G, Pizzi A (2010) Environmentally friendly wood preservative system based on polymerized tannin resin-boric acid for outdoor applications. Maderas-Cienc Tecnol 12:253-257

Tondi G, Wieland S, Wimmer T, Thevenon MF, Pizzi A, Petutschnigg A (2012a) Tannin-boron preservatives for wood buildings: mechanical and fire properties. Eur J Wood Wood Prod 70:689-696

Tondi G, Wieland S, Lemenagier N, Petutschnigg A, Pizzi A, Thevenon MF (2012b) Efficacy of tannin in fixing boron in wood: fungal and termites resistance. Bioresources 7:1238-1252

Tondi G, Palanti S, Wieland S, Thevenon MF, Petutschnigg A, Schnabel $\mathrm{T}$ (2012c) Durability of tannin-boron-treated timber. Bioresources 7: $5138-5151$

Tondi G, Thevenon MF, Pizzi A, Mies B, Standfest G, Petutschnigg A, Wieland S (2013a) Impregnation of scots pine and beech with tannin solutions: effect of viscosity and wood anatomy in wood infiltration. Wood Sci Technol 47:615-626

Tondi G, Schnabel T, Wieland S, Petutschnigg A (2013b) Surface properties of tannin-treated wood during natural and artificial weathering. Int J Wood Prod 4:150-157

Tondi G, Haurie L, Wieland S, Petutschnigg A, Lacasta A, Monton J (2014) Comparison of disodium octaborate tetrahydrate (DOT) and tannin-boron based formulations as fire retardant for wood structures. Fire Mater. doi:10.1002/fam.2186

Treu, A., Lückers, J., Militz, H. (2004) Screening of modified linseed oils on their applicability in wood protection, The international research group on wood protection, Document IRG WP 04-30346

Yamaguchi H, Okuda KI (1998) Chemically modified tannin and tannincopper complexes as wood preservatives. Holzforschung 52:596602

Yang I, Kuo M, Myers DJ (2006) Soy protein combined with copper and boron compounds for providing effective wood preservation. J Am Oil Chem Soc 83:239-245 